\title{
A clinical comparative study of two intubating doses of cis-atracurium during general anaesthesia for gynaecological surgery
}

\author{
Prakash Jammar*, Deba Gopal Pathak, Ismatara Begum, Ram Chandraji Chauhan
}

Department of Anaesthesiology, Silchar Medical College,

Silchar, Assam, India

Received: 13 March 2017

Accepted: 06 April 2017

*Correspondence to:

Dr. Prakash Jammar,

Email: dr.prakashjammar

@gmail.com

Copyright: (C) the author(s), publisher and licensee Medip Academy. This is an openaccess article distributed under the terms of the Creative Commons Attribution NonCommercial License, which permits unrestricted noncommercial use, distribution, and reproduction in any medium, provided the original work is properly cited.

\begin{abstract}
Background: Cisatracurium is one of the cis-cis isomer of atracurium (51W89:1R-cis 1'R-cis atracurium) an intermediate duration non-depolarising neuromuscular blocking drug and is devoid of histamine release. However, $2 \times$ ED95 dose of cisatracurium does not provide satisfactory intubating condition. The recommended intubating dose of cisatracurium is $3 \times$ ED95. The objective of this study was to evaluate and compare duration of action, hemodynamic effects and any adverse effects for different doses of cisatracurium.

Methods: After Institutional Ethical Committee approval and informed patient consent, 80 patients of ASA I and II in the age group of 20-60 years were selected and included in the study. Patients were divided in two groups of 40 each, group A received intravenously $3 \times \operatorname{ED} 95(0.15 \mathrm{mg} / \mathrm{kg})$ loading dose of cisatracurium and group B received intravenously 4×ED95 $(0.2 \mathrm{mg} / \mathrm{kg})$ loading dose of cisatracurium.

Results: After induction, MAP and HR shows decrease in both groups but neither statistically nor clinically significant. Better hemodynamic stability and longer duration of action was found in group B compared to group A. No adverse effects noted in both groups.

Conclusions: $4 \times$ ED95 dose of cisatracurium provides longer duration of action and more stable hemodynamic status than $3 \times$ ED95. No associated signs of histamine release were detected clinically.
\end{abstract}

Keywords: Cisatracurium, ED 95 doses, Hemodynamic stability, Histamine release

\section{INTRODUCTION}

Cisatracurium besilate is a cis-cis isomer (51W89:1R-cis 1 'R-cis atracurium), one of the 10 stereoisomers of atracurium that constitutes $15 \%$ of the atracurium mixture, an intermediate duration non-depolarising neuromuscular blocking drug. It is about three to four times more potent than atracurium and devoid of cardiovascular side effects in doses of upto 8 times of ED95. The ED95 of cisatracurium is $0.05 \mathrm{mg} / \mathrm{kg}^{1-5}$

The rate limiting step in the degradation of cisatracurium is Hoffmann degradation. (organ independent elimination) to form laudanosine and monoquaternary alcohol. $77 \%$ of drug is cleared via Hoffmann degradation which is a ph and temperature dependent process, rest $23 \%$ of drug get cleared through organ dependent means, and renal elimination accounts for $16 \%$ of this. Hydrolysis by non-specific esterases is not an important pathway for cisatracurium degradation. It is not associated with histamine release in humans. Although the liver and kidneys play only a small role in the excretion of cisatracurium besilate, urinary and hepatic elimination pathways are important for the metabolites of laudanosine..$^{5-8}$

The total body clearance (CL), steady-state $\mathrm{Vd}$ and elimination half-life of cisatracurium besilate in patients with normal organ function are approximately 0.27 to $0.34 \mathrm{~L} / \mathrm{h} / \mathrm{kg}(4.7 \mathrm{ml} / \mathrm{min} / \mathrm{kg}), 0.11$ to $0.16 \mathrm{~L} / \mathrm{kg}$ and 22 to 35 minutes, respectively. The volume of distribution $(\mathrm{Vd})$ 
of cisatracurium is small because of its relatively large molecular weight and high polarity. ${ }^{9}$

The magnitude of interpatient variability in the CL of cisatracurium besilate is low $(16 \%)$, a finding consistent with the strict physiological control of the factors that effects the Hofmann elimination of cisatracurium besilate (i.e. temperature and $\mathrm{pH}$ ). There is a unique relationship between plasma clearance and $\mathrm{Vd}$ because the primary elimination pathway for cisatracurium besilate is not dependent on organ function. ${ }^{9}$

The onset time, duration of action and recovery profile of cisatracurium is not affected by gender. ${ }^{10}$ The use of inhaled anaesthetics (like desflurane, sevoflurane) during anaesthesia induction and maintenance found to augment the neuromascular blocking effects of cisatracurium as compared with total i.v. anaesthesia. ${ }^{11}$

\section{METHODS}

After obtaining Institutional Ethical Committee approval (Silchar Medical College and Hospital, Silchar) and written informed consent from the patients, a prospective randomized clinical study was conducted. 80 female patients of American society of anaesthesiology (ASA) class I and II between the age group of 20-60 years planned for gynaecological operations were selected and included in the study.

\section{Exclusion criteria}

patient refusal; ASA class III and above; patients with systemic diseases like diabetes mellitus, hypertension, epilepsy; Patients on medication known to interact with neuromuscular blocking drugs e.g.: Antibiotics (aminoglycosides, tetracycline), antidepressants, anticonvulsants, antiarrhythmics (calcium channel blockers and quinidine) and magnesium sulphate and patients with known allergy to cisatracurium.

80 ASA I and II patients were divided into 2 groups A and B of forty $(n=40)$ each.

- Group A $(n=40)$ received cis-atracurium in the dose of $0.15 \mathrm{mg} / \mathrm{kg}$ body weight.

- Group B $(n=40)$ received cis-atracurium in the dose of $0.2 \mathrm{mg} / \mathrm{kg}$ body weight.

Pre-anaesthetic evaluation was done one day prior to surgery. All systems were examined including airway. Basic laboratory investigations were conducted including complete haemogram, urine analysis, blood sugar, kidney function test, chest X-ray and ECG (wherever applicable). All patients were given tablet Alprazolam 0.5 $\mathrm{mg}$ orally on the night before operation.

On arrival in the operation theatre, patients body weight was recorded. All routine monitoring devices were attached (NIBP, pulse oximeter, ECG). An 18G intravenous cannula was inserted in one of the hand and NIBP cuff on the other hand and baseline readings of mean arterial blood pressure (MAP), heart rate(HR), peripheral oxygen saturation (SPO2) were recorded. Patients were pre-medicated with inj. Glycopyrrolate 0.2 $\mathrm{mg}$ iv, inj. Ranitidine $50 \mathrm{mg}$ iv, Inj. Ondansetron $4 \mathrm{mg}$ iv, inj. Midazolam $1 \mathrm{mg}$ iv, inj. Tramadol $1.5 \mathrm{mg} / \mathrm{kg}$ body weight.

Patients were pre-oxygenated with $100 \%$ oxygen by facemask for 3 minutes. Patients were induced with i.v propofol @ $2 \mathrm{mg} / \mathrm{kg}$. Cis-atracurium in the abovementioned dosages was administered after the onset of propofol action (loss of response to verbal command). The patients were assist ventilated for the next 2 minutes and subsequently intubated with proper sized cuffed ET tube. Recordings of heart rate, mean blood pressure and $\mathrm{SpO} 2$ were recorded just before intubation, then at one min after intubation and then at $5 \mathrm{~min}, 10 \mathrm{~min}$ post intubation and then at every 10 min upto 1 hour of the study. After intubation EtCO2 was also recorded by connecting ETCO2 sensor to the ET tube. The anaesthesia was maintained with $02: \mathrm{N} 2 \mathrm{O}$ mixture in the ratio of $1: 2$ and with isoflurane in the concentration of 0.5 $-1 \%$.

The time of onset of action of cis-atracurium was fixed as 2 minutes at which intubation attempted.

The duration of action of cisatracurium was calculated from the time of administration of loading dose to the first maintenance dose administered.

Hemodynamic parameters (MAP, PR, $\mathrm{SPO}_{2}, \mathrm{ETCO}_{2}$ ) were compared till one hour of study from the time before induction (baseline recordings of parameters).

\section{Statistical analysis}

The data were compiled and analysed using Graph pad instat software 3, statistical software. For qualitative data, fischers exact test used and for quantitative data, student $t$ test used.

$\mathrm{P}$ value was determined. $\mathrm{p}>0.05$ - not significant, $\mathrm{p}<0.05-$ significant, $\quad \mathrm{p}<0.001$-highly significant, $\quad \mathrm{p}<0.0001$ extremely significant.

Demographic data, mean arterial blood pressure (MAP), Pulse Rate (PR), peripheral oxygen saturation $\left(\mathrm{SPO}_{2}\right)$, end tidal carbon dioxide $\left(\mathrm{ETCO}_{2}\right)$ were tabulated as Mean \pm standard deviation.

\section{RESULTS}

This study was conducted in an attempt to found duration of action of two intubating dosages of cisatracurium and to evaluate hemodynamic effects by comparing certain parameters such as- change in mean blood pressure (MAP), heart rate (PR), $\mathrm{SPO}_{2}$ and $\mathrm{ETCO}_{2}$ following 
induction and intubation as well as any side effects like hypotension, tachycardia etc.

Table 1: Demographic data.

\begin{tabular}{|llll|}
$\begin{array}{l}\text { Demographic } \\
\text { parameters } \\
\text { Mean } \pm \text { SD }\end{array}$ & $\begin{array}{l}\text { Group A } \\
(\mathbf{N}=40)\end{array}$ & $\begin{array}{l}\text { Group B } \\
(\mathbf{N}=40)\end{array}$ & $\begin{array}{l}\text { P } \\
\text { value }\end{array}$ \\
\hline Age (year) & $40 \pm 11.84$ & $40.80 \pm 8.69$ & 0.73 \\
\hline Weight (kg) & $52.17 \pm 8.61$ & $53.60 \pm 7.03$ & 0.42 \\
\hline ASA (I/II) & $15 / 25$ & $11 / 29$ & \\
\hline Inference & $\begin{array}{l}\text { Sample size were matched for age, } \\
\text { weight and ASA class. }\end{array}$ \\
\hline
\end{tabular}

Table 2: Comparison of mean duration of action (in minutes).

\begin{tabular}{|llll|}
$\begin{array}{l}\text { Mean duration } \\
\text { of action }\end{array}$ & $\begin{array}{l}\text { No. of } \\
\text { samples }\end{array}$ & Mean \pm SD & P value \\
\cline { 1 - 3 } Group A & $\mathrm{N}=40$ & $35.15 \pm 4.13$ & \multirow{2}{*}{$<0.0001$} \\
\hline Group B & $\mathrm{N}=40$ & $44.42 \pm 3.41$ & \\
\hline
\end{tabular}

The mean duration of action of cisatracurium intubating dose in Group A $(0.15 \mathrm{mg} / \mathrm{kg})$ was found to be 35.15 minutes \pm 4.13 (range: 31.02-39.28 minutes) while in Group B $(0.2 \mathrm{mg} / \mathrm{kg})$ it was found to be 44.42 minutes \pm 3.41 (range: 41.01-47.83 minutes). Group B shows longer duration of action than Group A, duration of action increases by only 9 minutes by increasing the dose from 0.15 to $0.2 \mathrm{mg} / \mathrm{kg}$.

\section{Hemodynamic variables}

Pre-induction vitals (MAP. PR, $\mathrm{SPO}_{2}$ ) were comparable in both groups with no statistically significant differences noted $(p>0.05)$. There was no clinical significant difference noted in $\mathrm{SPO}_{2}$ and $\mathrm{ETCO}_{2}$ values during the entire study in between the two groups. Changes in MAP and PR were considered clinically significant only when there is $>20 \%$ deviations from baseline values. Decrease in MAP and PR observed in both groups post induction but hemodynamic changes were comparable in both groups and not statistically significant $(\mathrm{p}>0.05)$.

There was rise of MAP and PR from baseline in the first 5-10 minutes post intubation in both groups but not clinically significant as changes were small, not $>20 \%$ deviations from baseline. Group B shows relatively more stable hemodynamics and lesser variability of MAP and PR from baseline than group A during the entire study period but this difference between two groups was not clinically significant (Table 3 and Table 4).

Table 3: Comparison of pulse rate.

\begin{tabular}{|llll|}
\hline Pulse rate Mean \pm SD & Group A & Group B & P value \\
\hline Baseline & $91.62 \pm 8.36$ & $90.70 \pm 7.88$ & 0.61 \\
\hline Prior intubation & $87.15 \pm 5.45$ & $87.40 \pm 5.35$ & 0.83 \\
\hline Post intubation & & & \\
\hline 1 min & $102.75 \pm 4.06$ & $99.57 \pm 3.35$ & 0.0003 \\
\hline 5 min & $98.02 \pm 3.00$ & $91.57 \pm 5.74$ & $<0.0001$ \\
\hline $10 \mathrm{~min}$ & $90.27 \pm 2.76$ & $85.20 \pm 5.86$ & $<0.0001$ \\
\hline $20 \mathrm{~min}$ & $89.25 \pm 2.58$ & $84.02 \pm 5.19$ & $<0.0001$ \\
\hline $30 \mathrm{~min}$ & $94.95 \pm 4.32$ & $84.02 \pm 5.19$ & $<0.0001$ \\
\hline $40 \mathrm{~min}$ & $91.02 \pm 4.12$ & $94.82 \pm 4.91$ & 0.0003 \\
\hline $50 \mathrm{~min}$ & $89.87 \pm 4.90$ & $83.62 \pm 5.58$ & $<0.0001$ \\
\hline $60 \mathrm{~min}$ & $94.05 \pm 4.99$ & $89.10 \pm 5.29$ & $<0.0001$ \\
\hline
\end{tabular}

Table 4: Comparison of MAP (mmHg).

\begin{tabular}{|llll|}
\hline MAP Mean \pm SD & Group A & Group B & P value \\
\hline Baseline & $102.67 \pm 6.23$ & $102.80 \pm 5.81$ & 0.92 \\
\hline Prior intubation & $97.82 \pm 14.52$ & $100.82 \pm 4.29$ & 0.21 \\
\hline Post intubation & & & $<0.0001$ \\
\hline $1 \mathrm{~min}$ & $111.65 \pm 6.99$ & $100.85 \pm 3.96$ & $<0.0001$ \\
\hline $5 \mathrm{~min}$ & $106.77 \pm 8.59$ & $95.82 \pm 5.38$ & 0.0147 \\
\hline $10 \mathrm{~min}$ & $103.12 \pm 6.76$ & $99.25 \pm 7.12$ & $<0.0001$ \\
\hline $20 \mathrm{~min}$ & $103.30 \pm 4.82$ & $98.07 \pm 4.33$ & $<0.0001$ \\
\hline $30 \mathrm{~min}$ & $110.80 \pm 4.36$ & $103.20 \pm 3.05$ & $<0.0001$ \\
\hline $40 \mathrm{~min}$ & $103 \pm 6.43$ & $111.85 \pm 3.59$ & 0.0083 \\
\hline $50 \mathrm{~min}$ & $102.67 \pm 1.84$ & $103.72 \pm 1.61$ & 0.14 \\
\hline $60 \mathrm{~min}$ & $108.4 \pm 15.99$ & $104.55 \pm 3.82$ & \\
\hline
\end{tabular}




\section{DISCUSSION}

While selecting neuromuscular agent for tracheal intubation or skeletal muscle relaxation, main aim of an anaesthesiologist is to select an agent with Rapid onset; longer clinical duration of action; better hemodynamic stability and Good spontaneous reversal. In present study, we have studied cisatracurium for its duration of action and hemodynamic stability. Various studies have been conducted earlier on cisatracurium to determine pharmacokinetics, pharmacodynamics, safety and efficacy.

Amini Shahram et al studied effects of different doses of cisatracurium on appropriate time for endotracheal intubation and hemodynamic changes during anaesthesia and found that the mean clinical duration of action (recovery of evoked response to $25 \%$ of control) with $0.15 \mathrm{mg} / \mathrm{kg}$ was $44.93 \pm 5.40$ minutes while with $0.2 \mathrm{mg} / \mathrm{kg}$ was $57.03 \pm 4.21$ minutes.12 Luc Bergeron et al found that mean clinical duration of action with $0.15 \mathrm{mg} / \mathrm{kg}$ body $\mathrm{wt}$. was $58.9 \pm 10.4$ minutes. $^{13}$

As seen with other nondepolarising neuromuscular agents, increasing the dose decreases the time of onset of block at the expense of prolonging the time to spontaneous recovery. Linda S, Bluestein MD, et al found that increasing the dose of cisatracurium from 0.1 to 0.15 and to $0.2 \mathrm{mg} / \mathrm{kg}$ increases the duration of action by only 9 and 16 minutes respectively and also reported that higher doses provides rapid onset. ${ }^{14}$ Similar findings were observed by ShangGuan W et al. ${ }^{15}$

Infants are more sensitive to effects of neuromuscular blocking drugs than children. Taivainen $\mathrm{T}$ et al studied safety and efficacy of cisatracurium $0.15 \mathrm{mg} / \mathrm{kg}$ during nitrous oxide opioid anaesthesia in infants and children, found that onset of action was more rapid in infants than children and mean clinical duration of action of cisatracurium $0.15 \mathrm{mg} / \mathrm{kg}$ loading dose in infants was $43.3 \pm 6$ minutes while in children was $36.0 \pm 5.4$ minutes with $\mathrm{p}$ value $<0.0001 .{ }^{16}$ Sarooshian SS et al also found that young patients have more rapid onset of block than elderly patients because of slow biophase equilibration in elderly patients but clinical duration of action i.e. recovery profile was found to be similar between two groups. ${ }^{17}$ Similar findings were observed by Ornstein E et al. ${ }^{18}$

In present study the mean clinical duration of action with $0.15 \mathrm{mg} / \mathrm{kg}$ was found to be $35.15 \pm 4.13$ minutes while that with $0.2 \mathrm{mg} / \mathrm{kg}$ was found to be $44.42 \pm 3.41$ minutes which correlates with the findings of previous studies.

El-Kasaby AM et al observed that small changes occurred in mean blood pressure and heart rate post induction and post intubation but these changes were not statistically and clinically significant at higher doses of cisatracurium and so hemodynamic stability were more evident among higher doses of cisatracurium $\left(4 \times\right.$ ED95, $6 \times$ ED95) ${ }^{19}$
Similar findings were also observed by Taivainen $\mathrm{T}$ et al, Shahram A et al. ${ }^{12,16}$ These observations of hemodynamic effects of cisatracurium correlates with the observations of our study where group B ( $0.2 \mathrm{mg} / \mathrm{kg}=4 \times \mathrm{ED} 95)$ found to be hemodynamically more stable than group A $(0.15$ $\mathrm{mg} / \mathrm{kg}=3 \times \mathrm{ED} 95)$.

Recommended intubating dose of cisatracurium is 0.15 $\mathrm{mg} / \mathrm{kg}$. Intubating conditions following administration of different doses of cisatracurium evaluated in patients undergoing anaesthesia with propofol-isoflurane. Carroll MT et al observed that a dose of $0.15 \mathrm{mg} / \mathrm{kg}$ of cisatracurium provides clinically acceptable intubating conditions (good or excellent) in nearly all patients within 2 minutes and at a lower dose $(0.1 \mathrm{mg} / \mathrm{kg})$ time required to achieve clinically acceptable intubating conditions was more than 2 minutes. ${ }^{20}$ In our study, good to excellent intubating conditions were observed in nearly all patients of both groups at 2 minutes, so our study observations correlate with observations of other studies.

No adverse effects attributable to cisatracurium were observed during our study.

\section{CONCLUSION}

In summary, Cisatracurium is a potent intermediate acting non-depolarizing neuromuscular blocking agent and tracheal intubation can be accomplished with good to excellent intubating conditions at 2 minutes following $0.15 \mathrm{mg} / \mathrm{kg}$ and $0.2 \mathrm{mg} / \mathrm{kg}$ of cisatracurium. Increasing the dose from 0.15 to $0.2 \mathrm{mg} / \mathrm{kg}$ increases the mean clinical duration of action only by 9 minutes but hemodynamic stability is relatively better at higher doses. The principal advantage of cisatracurium is lack of histamine release which provides better cardiovascular stability in comparison to atracurium and other histamine releasing neuromuscular blocking agents.

Faster onset and longer duration of action with larger doses of cisatracurium (4xED95 and above) and more cardiovascular stability, predictable recovery from neuromuscular block make cisatracurium a more promising alternative muscle relaxant agent for tracheal intubation in clinical practice.

\section{Funding: No funding sources \\ Conflict of interest: None declared \\ Ethical approval: The study was approved by the Institutional Ethics Committee}

\section{REFERENCES}

1. Lien CA, Schmith VD, Belmont MR. Pharmacokinetics of cisatracurium in patients receiving nitrous oxide/opioid/barbiturate anesthesia: Anesthesiol. 1996;84:300-8.

2. Lien CA, Belmont MR, Abalos. The cardiovascular effects and histamine-releasing properties of 51W89 
in patients receiving nitrous oxide/opioid/barbiturate anaesthesia. Anesthesiol. 1995;82:1131-8.

3. Lepage, Jean-Yves, Malinovsky, Jean-Marc. Pharmacodynamic dose- response and safety study of cisatracurium (51W89) in adult surgical patients during N2 O-O2-opioid anesthesia. Anesthesia Analgesia. 1996;83(4):823-9.

4. Mellinghoff $H$, Diefenbach C. The clinical pharmacology of cisatracurium. Anaesth. 1997;46(6):481-5.

5. Konstadt Steven N, Reich David L, Stanley Thomas E. A two-center comparison of the cardiovascular effects of cisatracurium (Nimbex Trademmark) and vecuronium in patients with coronary artery disease. Anesth Analges. 1995;81(5):1010-4.

6. Welch RM, Brown A, Ravitch J, Dahl R. The in vitro degradation of cisatracurium, the $\mathrm{R}$, cis- $\mathrm{R}$ '-isomer of atracurium, in human and rat plasma. Clin Pharmacol Ther. 1995;58(2):132-42.

7. 7. Sparr HJ1, Beaufort TM, Fuchs-Buder T. Newer neuromuscular blocking agents: how do they compare with established agents? Drugs. 2001;61(7):919-42.

8. Doenicke A, Soukup J, Hoernecke R. The lack of histamine release with cisatracurium: a double-blind comparison with vecuronium. Anesth Analg. 1997;84:623-8.

9. Bryson HM, Faulds D. Cisatracurium besilate. A review of its pharmacology and clinical potential in anaesthetic practice: Drugs. 1997;53(5):848-66.

10. Adamus M, Gabrhelik T, Marek O. Influence of gender on the course of neuromuscular block following a single bolus dose of cisatracurium or rocuronium. Eur J Anaesthesiol. 2008;25(7):589-95.

11. Wulf H, Kahl M, Ledowski T. Augmentation of neuromuscular blocking effects of cisatracurium during desflurane, sevoflurane, isoflurane or total i.v. anaesthesia. Br J Anaesth. 1998;80;308-12.

12. Shahram A, Ali A, Masoud R. Comparison of the effects of different doses of cisatracurium on appropriate time for endotracheal intubation and hemodynamic changes during anesthesia. Zahedan $\mathbf{J}$ Res Med Sci. 2011;13(7):13-6.

13. Bergeron L, Bevan DR, Berrill A. Concenterationeffect relationship of cis-atracurium at three different dose levels in the anaesthetized patient. Anaesthesiol. 2001;95:314-23.

14. Bluestein LS, Stinson LW, Lennon RL. Evaluation of cisatracurium, a new neuromuscular blocking drug, for tracheal intubation. Can $\mathrm{J}$ Anaest. 1996;43(8):925-31.

15. ShangGuan W, Lian Q, Li J, Gao F. Clinical pharmacology of cisatracurium during nitrous oxidepropofol anesthesia in children. J Clin Anesth. 2008;20(6):411-4.

16. Taivainen T, Meakin GH, Meretoja OA. The safety and efficacy of cisatracurium $0.15 \mathrm{mg} / \mathrm{kg} 21$ during nitrous oxide \pm opioid anaesthesia in infants and children. Anaesth. 2000;55:1047-51.

17. Sarooshian SS, Michael A, Stafford. Eastwood NB. Pharmacokinetics and pharmacodynamics of cisatracurium in young and elderly adult patients. Anaesthesiol. 1996;84:1083-91.

18. Ornstein E, Lien CA, Matteo RS. Pharmacokinetics and pharmacodynamics of cisatracurium in geriatric surgical patients. Anaesthesiol. 1996;84:520-5.

19. El-Kasaby AM, Atef HM, Helmy AM. Cisatracurium in different doses versus atracurium during general anaesthesia for abdominal surgery. Saudi J Anaesthe. Saudi J Anaesth. 2010;4(3):152-7.

20. Carroll MT, Mirakhur RK, Lowry D. A comparison of neuromuscular blocking effects and reversibility of cisatracurium versus atracurium. Anaesthe. 1998;53:744-8.

Cite this article as: Jammar P, Pathak DG, Begum I, Chauhan RC. A clinical comparative study of two intubating doses of cis-atracurium during general anaesthesia for gynaecological surgery. Int $\mathrm{J}$ Basic Clin Pharmacol 2017;6:1206-10. 